\title{
Using sUAS-Acquired Imagery to Map Landslide Susceptibility along the Lake Michigan Shoreline of Wisconsin
}

\author{
Itai Bojdak-Yates ${ }^{\mathrm{a}}$, Elliott Marsh ${ }^{\mathrm{a}}$, Cal McCormick ${ }^{\mathrm{b}}$, Tyler Scott ${ }^{\mathrm{a}}$
}

\begin{abstract}
a. Geosciences, Lawrence University, Appleton, WI. b. Geographic Information Science, Carthage College, Kenosha, WI
\end{abstract}

\begin{abstract}
Bluffs along the Wisconsin shoreline of Lake Michigan frequently collapse, and this collapse often occurs due to saturation and weakness in a sand layer present in the bluffs. We used an sUAS to collect visible and thermal imagery of bluffs along Lake Michigan in Kewaunee County, WI. We then proceeded to classify this imagery in ArcGIS Pro to determine whether the program's classification tools could locate the sand layer. Furthermore, we examined imagery before and after a major storm to determine the storm's effect on water content in the sand layer. Our results indicate that we can use automated computer programs to classify the sand layer based on a combination of visible and thermal imagery. Additionally, we found that large summer storms do not significantly alter the saturation of the sand layer and infer that their effect on bluff collapse is minimal.
\end{abstract}

\section{Introduction}

The bluffs along Lake Michigan near Two Creeks, Wisconsin, (Kewaunee and Manitowoc counties, Fig. 1) are a geologically significant site. These bluffs contain the famous "Two Creeks Buried Forest," which has garnered the interest of glacial geologists, paleoclimatologists and geo-tourists for over a century. These bluffs have also been prone to failures over the years: one landowner with whom we spoke lost over 12 feet of property in the past couple of years due to high lake levels and bluff failures. The property owner next door spent $\$ 50,000$ installing riprap on their property in an attempt to prevent a similar retreat near their restaurant. With lake levels rapidly changing and reaching record highs, the bluffs will continue to erode rapidly, and property owners are struggling to keep up.

Starting from the bottom (Fig. 2), the bluff consists of a till overlain by a laminated silt and clay layer; then a sand and gravel layer; then silts and sands containing wood fragments; then the Valders till layer; and finally, recent colluvium on the surface (Lee and Horn, 1972). Since these bluffs are prone to failures, many of the layers are covered with colluvium made up of soil from all the layers, making the intact layers harder to identify visually. The tills are stiff and have low permeability, while the sand layer is much more permeable. The sand layer is also the weakest layer in the bluff, especially in contrast to the tills. This contrast in strength means that the sand layer often fails first. Saturation of the sand layer further weakens it, and with the less permeable clay layer below, the sand can become very saturated as water piles on top of the clay. Sufficient saturation can easily trigger a collapse (Bay-Lake Regional Planning Commission, 1996).

Funding and resources provided by the Wisconsin Space Grant Consortium and Lawrence University. Advice and guidance provided by Jeffrey Clark, Geosciences, Lawrence University. 

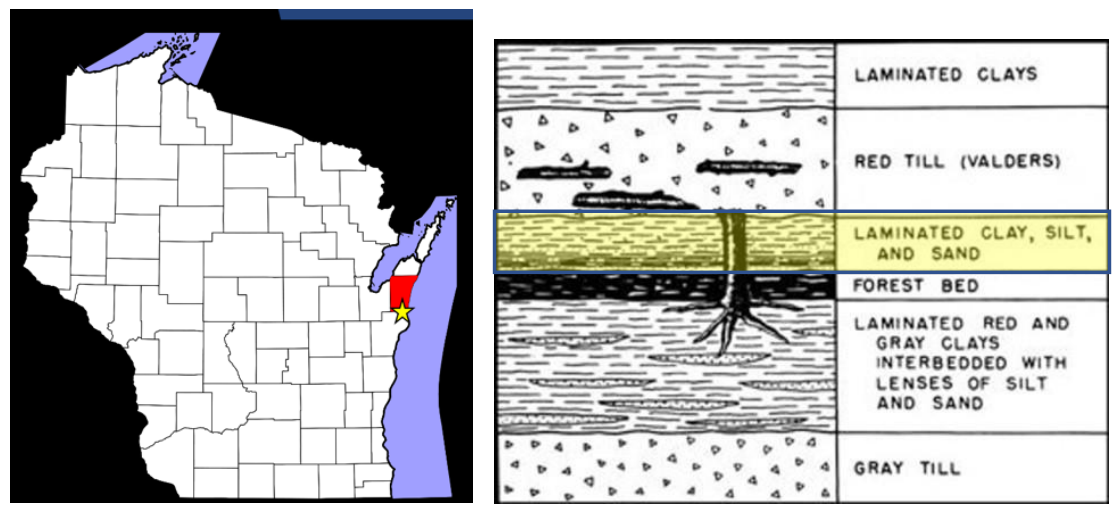

Figure 1 (left): map of Wisconsin with Kewaunee County in red and the study site marked by a star.

Figure 2 (right): stratigraphic column of Two Creeks from a National Parks Service document ("Two Creeks Section," 2005). The sand layer of interest is highlighted in yellow.

There have been many previous studies at this site which provide ample information about its past. One such study (Brown et al., 2005) examined the temporal variables that affect bluff recession on the shores of Lake Michigan, such as wave height and precipitation. An additional study (Hart et al., 2020) demonstrated that a thermal sensor can be used to detect how saturated the sand layer is. 3D mapping is also useful to identify short term changes on the bluff (Volpano et al., 2020).

Using all this information, along with a drone equipped with visual and thermal sensors, we were able to map and analyze not only the bluff, but the sand layer itself. We were also able to devise a way to identify the sand layer using machine learning. We know from previous studies that drones can be used to map bluff erosion and that there are many temporal variables that affect bluff stability. Our work adds to this body of knowledge with a way to identify the locations of weak layers (spatial variables) and apply these classification methods to existing datasets.

\section{Materials and Methods}

Study site. To accomplish the team's objective, a study site needed to be found that would allow access to bluffs on Lake Michigan to place control point targets and had an exposed sand layer that could be captured using an sUAS. The study site we located in Kewaunee County, WI, (at $44.32779^{\circ} \mathrm{N}, 87.54368^{\circ} \mathrm{W}$ ) was able to accomplish both goals (Fig. 1). Moreover, this site allowed us to include a temporal aspect in our data, as it allowed multiple drone flights over the span of three weeks in July and August. This site is about an hour's drive east of Lawrence University in Appleton, WI, where our team was based. In the planning stages of this project, the landowners along the bluff were contacted, and permission was granted to use a stretch of riprap installed by a local restaurant, Gib's on the Lake, and to fly over the property of another landowner on the chosen study site.

Field methods. To ensure consistent and accurate results over multiple flights on different days, we established a common procedure so that missions could be replicated. Using a Emlid Reach RS2 GNSS system, the team logged site coordinates to a base station for four hours, which allowed accurate marking of targets using a rover unit (RTK surveying). To accurately georeference the drone imagery, flags were placed into the bluff. The flags stayed at the same locations throughout the three-week flight period, and their coordinates were measured using the Emlid system to an accuracy within 2 centimeters. These flags were then 
used to place bigger markers with either a black and white box pattern or an "X" pattern. These targets were used to ensure the flags could be seen from both the visual and thermal cameras. In the case of the thermal camera, the targets could be seen through the uneven heating of the black and white portions of the markers. Once the markers were placed, a DJI Matrice V200 quadcopter equipped with a Zenmuse XT2 camera would take two flights along the bluffs at 25 and 12 meters above the beach. The 25-meter flight was for the visual camera, as the distance allows the camera to capture the whole bluff to create a 3D model, while the 12-meter flight was for the thermal camera to get closer to the sand layer and solely focus on the face of the bluff. The visual camera had a resolution of 12 megapixels and a ground cell resolution of 0.7 centimeters, while the thermal camera had a resolution of 0.5 megapixels and a ground cell resolution of three centimeters.

In addition, we took soil samples of the sand layer over the course of the project to determine its moisture content. We used these samples to map the change in soil moisture of the sand layer in the days prior to and after the storm event. We also measured the temperature with a handheld thermal gun (a Fluke VT02 Visual IR Thermometer). The temperature data allowed us to ground truth the thermal data from the drone and to further monitor changes in soil moisture content over the course of the project.

Lab methods. Once a flight was completed, the resulting batch of photos was loaded into Agisoft Metashape. This program uses structure from motion photogrammetry to align and stitch together photos and produce products such as point clouds, DEMs, and orthomosaics. We georeferenced these products to real-world coordinates using our ground control points, hus allowing the images to be accurately overlaid in subsequent processing. Once the orthomosaics were built and georeferenced, we loaded them into ArcGIS Pro and classified them using the unsupervised classification wizard. In the case of thermal imagery, the raster values from the Zenmuse XT2 needs to be converted to Celsius, which was done through the raster calculator in ArcGIS Pro using this formula: (Band $1 * 0.04-273.15$ ). Through this formula, raster values can be directly compared in Celsius, and these flights can be easily compared to other thermal flights working in a common temperature system.

While image processing occurred in Metashape, ArcGIS Pro was used to work on classification of single images to test the computer's ability to locate and distinguish the sand layer. In ArcGIS, the classification wizard was used to run an unsupervised classification where the image was separated into three classes through pixel values (either RGB or thermal values). These classes were then categorized by the user as either the "sand layer", "till", or "vegetation" layer. This separation into three classes allows for the vegetation to have a distinct class, while the "till" layer serves as a catch-all for the portions of the bluff that are not the sand layer.

Along with utilizing photos from the drone flights, the soil samples taken were gravimetrically analyzed for their moisture content. The samples were placed on aluminum weighing pans, weighed initially, and then put into a lab heating and drying oven for eight hours at 100 degrees Celsius. After this, the samples were weighed again to determine how much moisture had been held inside the sample, using the weight decrease of the sample as the estimation method.

We now had classified visible and thermal images in ArcGIS Pro as well as moisture content and temperature data from the sand layer. This data would allow us to determine whether the sand 
layer could be accurately classified by a computer and whether a storm could significantly alter the saturation of the sand layer and trigger bluff failures.

\section{Classification of the Sand Layer}

The use of classification on individual pictures showed some distinction between the sand layer and till layer (Fig. 3.A-B). Additionally, the computer picked up the vegetation in detail along the bluff. When using thermal imagery to classify the sand layer, we kept the settings constant to compare the results with the visible. Using the unsupervised pixel-based tool with the same predefined classes, the thermal was able to clearly identify the sand layer as distinct from the till layer (Fig. 3.C-D). Also, using thermal imagery the vegetation thermal signature was generally cooler than the sand layer; however, in some areas of the bluff the vegetation thermal signature became confused with the sand layer (Fig. 3D).

We experimented with a supervised pixel-based setting in the classification wizard. This strategy resulted in either poor identification of the sand layer or unidentified classes of the two, making it difficult to distinguish between the classes. Using object-based classification in both unsupervised and supervised schemes gave us long processing times that ended in failure. We found it best to use pixel-based unsupervised classification for the more accurate classification. Additionally, we can more easily apply this scheme to any picture of the bluff to identify the sand layer.

We chose the thermal imagery for the best results as it distinguishes between the sand layer and till layer even with colluvium. The thermal succeeds at this because the colluvium is notably warmer than the sand layer; the sand layer's higher water content keeps its temperature more stable. ArcGIS Pro can map out the sand layer with both visible and thermal imagery, but we conclude thermal is the best for classification since it shows a clearer distinction between the sand and till and a reasonable distinction between the sand and vegetation.

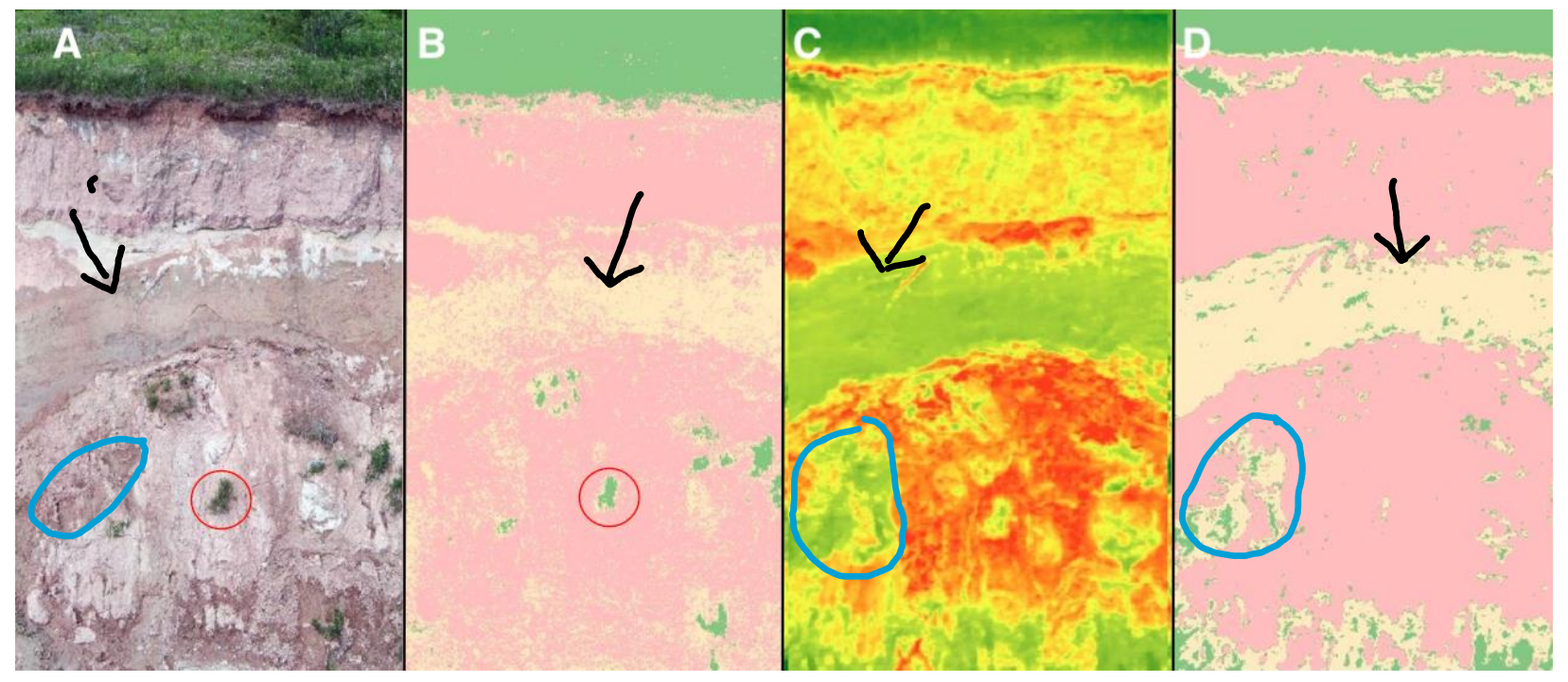

Figure 3: Single photograph of a section of the bluff. A is visible imagery with clear distinguishable sand (arrows) and till layer (above and below). The vegetation on the bluff is circled in red. B is a classification of the visible with three distinct classes: vegetation (green), till layer (pink), and sand layer (tan). C is s false-color thermal photograph of the bluff - green is cooler, red is warmer. D is a classification of the thermal with the same categories. The blue circled area is a cooler patch of colluvium. 
Wisconsin Shoreline Inventory and Oblique Viewer (http://floodatlas.org/asfpm/oblique_viewer/) is a preexisting database that shows the risk of bluff failure and provides oblique photos for the entire Wisconsin shoreline going back to 1976. We took some of these images into ArcGIS Pro and used the same scheme developed for our images on the oblique viewer's photos. The results show the sand layer is somewhat distinguishable from the other layers but isn't as clear as in our imagery due to some differences in photography. The time of day during which the imagery was taken makes a difference because of shadows, which shade out the bluff. Time of year makes a difference as well, since vegetation is easier to distinguish when it is green in summer. Photos taken at a greater distance from the bluffs decrease the ground cell resolution, making classifying more difficult. Finally, the inclusion of a thermal camera would allow for better distinction between till and sand layers. We believe that imagery taken during the summer between $10 \mathrm{am}$ and $12 \mathrm{pm}$, using visible and thermal cameras, and taken relatively close to the bluffs would create a dataset which could be used to accurately delineate the sand layer using our methodology. This data could be added to preexisting databases for risk assessment along the Wisconsin shoreline and support homeowners, construction companies, and anyone else concerned about bluff retreat.

\section{The Effect of Storms on Soil Moisture and Bluff Stability}

On July $14^{\text {th }}, 2021$, a 50 -year storm blew across eastern Wisconsin. This storm dumped 4.9 inches of rain on Two Rivers, a town roughly $20 \mathrm{~km}$ south of the study site, in less than 24 hours. (For context, 4.9 inches is $150 \%$ of the average rainfall for all of July at Two Rivers.) We collected images of the bluffs on 7/13, 7/15, 7/16, 7/17, 7/19, and 8/4 (Fig. 4).

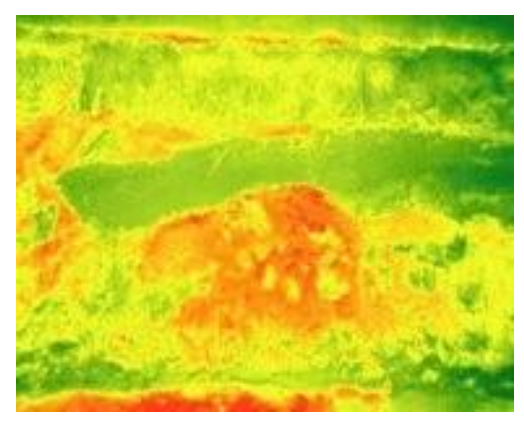

y 13

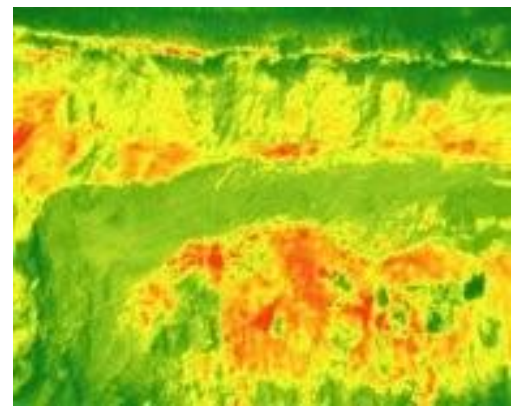

D. July 17

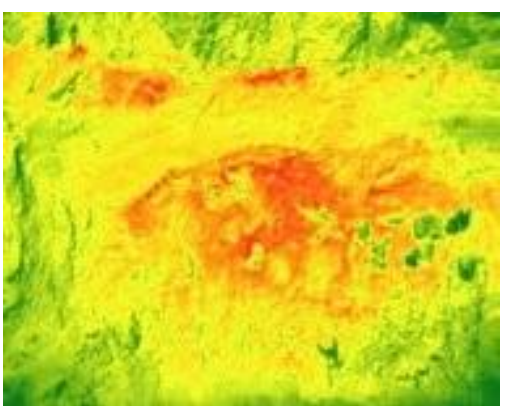

B. July 15

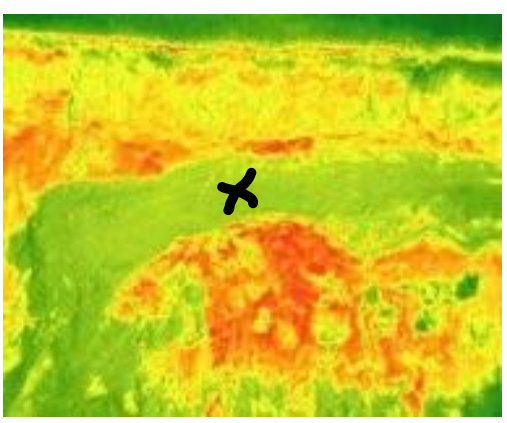

E. July 19

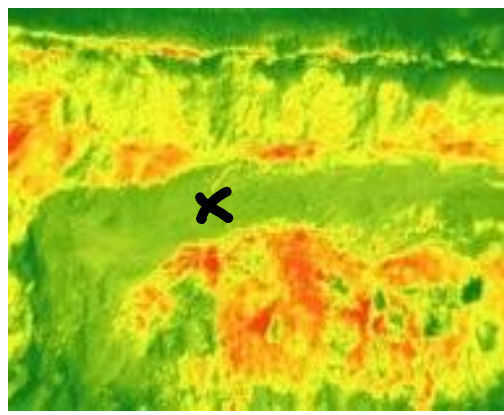

A. Jul

\section{July 16}

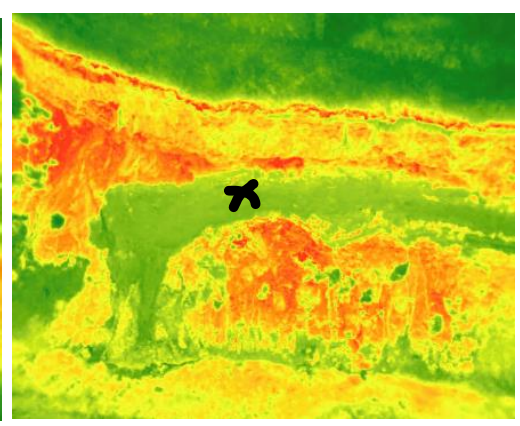

F. August 4

Figure 4: Thermal images of the same section of bluff on different days. Red is warmer, green is colder, and absolute temperatures are not the same in all photos (i.e., dark red in 4.A does not indicate the same absolute temperature as dark red in 4.B). For the black Xs, see Table 1.

On 7/13, the day before the storm in question, the sand layer appeared cooler (green) and thermally distinct (thick band across middle of Fig. 4.A) due to its relatively high moisture content. The sand 
layer remained cool due to lower groundwater temperatures and evaporative cooling throughout the morning. The rest of the bluff appeared warmer (red and yellow) because it was dry after about a week without rain. On $7 / 15$ the sand layer appeared thermally similar to the till (Fig. 4.B), as evidenced by the disappearance of the green band. This change occurred because the storm the day before soaked the till and colluvium, so the entire bluff was subject to evaporative cooling. On the remaining days the images appeared remarkably similar to each other and to the imagery from the $13^{\text {th }}$, and the sand layer appeared quite distinct (Fig. 4.C-F).

Absolute temperature data, which was measured with both the thermal imagery above and the Fluke handheld thermometer, did not show any trends following the storm. This suggests that no dramatic changes in water content occurred, as increased saturation would likely have led to a lower temperature by late morning. Additionally, gravimetric moisture content measurements of soil samples taken from the sand layer on the $12^{\text {th }}, 16^{\text {th }}$, and $19^{\text {th }}$ of July further supported the lack of change in moisture (Table 1). Had the storm led to an increase in the moisture content of the sand layer, we expect we would have seen that increase in our hand samples. The fact that no such increase occurred in our hand samples indicates that it did not occur in the sand layer as a whole. Based on these data, we conclude that there was no meaningful change in the moisture content of the sand layer following the storm.

\begin{tabular}{|l|l|}
\hline Date & Moisture Content (mass \%) \\
\hline $7 / 12$ & 11.12 \\
\hline $7 / 16$ & 11.29 \\
\hline $7 / 19$ & 12.71 \\
\hline $8 / 4$ & 10.70 \\
\hline
\end{tabular}

Table 1: Moisture content of soil samples. These samples were collected at the locations of the black Xs in Fig. 4.C, $\mathrm{E}$, and $\mathrm{F}$.

In addition, no large-scale (scarp-producing) failures occurred within the study site following the storm. We did see some obvious shifts in the colluvium (including the burial of one of our flag markers), but no measurable retreat of the bluff that might threaten property. The fact that no large-scale failures occurred following a 50-year storm and that the sand layer saw no meaningful long-term (multi-day) change in moisture content leads us to conclude that summer storms do not play a significant role in triggering bluff failures.

This conclusion concurs with Volpano et al. (2020), who argue that spring snowmelt is responsible for most bluff failures, not summer storms. This counterintuitive mechanism is believed to be a result of the low permeability of soils in Kewaunee and Manitowoc counties. These soils tend to be clayey and have a high runoff potential and low infiltration rate (USDA, 2007), especially when saturated. As a result, large summer storms will simply wash off the top of the soil instead of infiltrating. Spring snowmelt, however, comes more slowly (akin to light, steady rain over a few weeks), and more of the water can infiltrate into the sand layer. Thus, the sand layer becomes saturated and prone to failure in the spring, while it remains relatively stable in the summer.

These temporal results can further assist efforts to reduce erosion damage along Lake Michigan. Further research could determine whether most bluff failures do, in fact, occur in the spring. This information in turn could assist property owners and land management agencies in knowing when 
to watch for failures or avoid new construction on bluffs. Understanding that snowmelt infiltration, rather than summer storms, is responsible for bluff failure can also inform mitigation efforts to keep bluffs from collapsing in the first place.

\section{Conclusions}

Our findings suggest that ArcGIS classification tools can successfully locate sand layers in bluffs using visible and thermal imagery. While these tools do not do their job perfectly, they provide an automated way to locate potential sand layers and thus contribute to existing risk-assessment datasets. Additionally, future flights for the purpose of collecting imagery can use the methods detailed here and attempt to fly at closer range to the bluffs, fly during late morning in the summer, and use both visible and thermal cameras. Flights such as these would allow a computer to identify sand layers quickly and accurately throughout Wisconsin and add an important set of data to risk assessment plans.

Additionally, our findings support previous conclusions about the time of year when bluff failure occurs. The lack of failure following a 50-year storm implies that summer storms rarely, if ever, trigger large-scale bluff collapse. This information could also be fed into risk assessment plans, both for its temporal aspect and for its insights into the mechanisms through which bluffs collapse.

\section{Acknowledgements}

We would like to thank the National Aeronautics and Space Administration, Wisconsin Space Grant Consortium, and Lawrence University for providing us with funding and resources. We would also like to thank our project advisor Jeff Clark for providing us with guidance and support throughout this project.

Many thanks as well to Gib's on the Lake Supper Club and other property owners for allowing us to conduct research on their property.

\section{References}

Bay-Lake Regional Planning Commission. (1996). Lake Michigan Shoreline Recession and Bluff Stability in Northeastern Wisconsin: 1996.

Brown, E. A., Wu, C. H., Mickelson, D. M., \& Edil, T. B. (2005). Factors Controlling Rates of Bluff Recession at Two Sites on Lake Michigan. Journal of Great Lakes Research, 31(3), 306321. doi: 10.1016/S0380-1330(05)70262-8

Hart, D. J., Swanson, K., \& Rawling III, J. E. (2020). Final Report: Aerial thermal imaging applied to Wisconsin's groundwater, springs, thin soils, and slopes. Retrieved from the University of Wisconsin Water Resources Institute website: https://www.wri.wisc.edu/wpcontent/uploads/DATCP2020-3.pdf

Lee, G. B., \& Horn, M. E. (1972). Pedology of the Two Creeks Section, Manitowoc County, Wisconsin. Wisconsin Academy of Sciences, Arts, and Letters. 60, 183-199.

National Cooperative Soil Survey. (2011, January). Kewaunee Series. Retrieved from https://soilseries.sc.egov.usda.gov/OSD_Docs/K/KEWAUNEE.html 
National Park Service. (2005). Fig. 7: Idealized Two Creeks Section. After Prouty (1960, Fig. 12). Geology of Ice Age National Scenic Reserve of Wisconsin. Retrieved from https://www.nps.gov/parkhistory/online_books/science/2/chap2.htm

USDA Natural Resources Conservation Science. (2007, May). Chapter 7: Hydrologic Soil Groups. In Part 630 Hydrology National Engineering Handbook. Retrieved from https://directives.sc.egov.usda.gov/OpenNonWebContent.aspx?content=17757.wba

Volpano, C. A., Zoet, L. H., Rawling III, J. E., Theuerkauf, E. J., \& Krueger, R. (2020). Threedimensional bluff evolution in response to seasonal fluctuations in Great Lakes water levels. Journal of Great Lakes Research, 46(6), 1533-1543. Doi: 10.1016/j.jglr.2020.08.017 